\title{
BASE NACIONAL COMUM PARA FORMAÇÃO DE PROFESSORES DA EDUCAÇÃO BÁSICA: em foco os jogos políticos e a responsabilização docente
}

\author{
Débora Raquel Alves Barreiros \\ Universidade do Estado do Rio de Janeiro - UERJ, Brasil \\ Rosalva de Cássia Rita Drummond \\ Instituto Superior de Educação do Rio de Janeiro - ISERJ, Brasil
}

\begin{abstract}
Resumo
O artigo tem por objetivo discutir a formação de professores a partir da política governamental da Base Nacional Comum para Formação de Professores da Educação Básica (BNC-Formação e BNCFormação Continuada), problematizando as noções relacionadas aos direitos de aprendizagem, espectro de justiça e a responsabilização docente, em detrimento dos sentidos mais amplos do Direito à Educação. Do ponto de vista teórico-metodológico, a nossa proposta se pauta numa leitura pós-estrutural das políticas de currículo para formação de professores homologadas pelo Conselho Nacional de Educação em 2019 e 2020, em diálogo com Bhabha (2008), Macedo (2006), Derrida (2010) com vistas a desconfiar dos sentidos em que se veiculam as ideias de direito nas políticas instituídas no governo atual. Consideramos que as políticas curriculares voltadas para a formação de professores, como foi proposta pela BNC-Professores, reforçam o poder regulatório e normativo do governo, assim como propõem um projeto pautado no desempenho, na excelência e na eficiência da prática dos professores a partir de mecanismos de avaliação interna e externa. Além de transferir responsabilidade pela aprendizagem para os professores e instituições, resultando num movimento de perda de autonomia docente e de identidade profissional.
\end{abstract}

Palavras-chave: BNC-Professores; Currículo; Formação de Professores.

\begin{abstract}
The article aims to discuss teacher training based on the government policy of the Common National Base for Teacher Training of Basic Education (BNC-Training and BNC-Continuing Education), problematizing the notions related to learning rights, spectrum of justice and teacher accountability, to the detriment of the broader meanings of the Right to Education.. From a theoreticalmethodological point of view, our proposal is based on a post-structural reading of curriculum policies for teacher training approved by the National Council of Education in 2019 and 2020, in dialogue with Bhabha (2008), Macedo (2006), Derrida (2010) with a view to distrusting the meanings in which the ideas of law are conveyed in the policies instituted in the current government. We consider that curriculum policies aimed at teacher education, as proposed by BNC-Teachers, reinforce the regulatory and normative power of the government, as well as propose a project based on the performance, excellence and efficiency of teachers' practice from internal and external evaluation mechanisms. In addition to transferring responsibility for learning to teachers and institutions, resulting in a movement of loss of teacher autonomy and professional identity.
\end{abstract}

Keywords: BNC-Teachers; Curriculum; Teacher training.

ISSN 1645-1384 (online) www.curriculosemfronteiras.org 
O contexto atual tem sido marcado por viés ultraconservador e autoritário no âmbito das decisões governamentais e no campo políticas públicas educacionais. Atravessadas por essa crise ética, então, que nos propomos discutir a formação de professores a partir da política governamental da Base Nacional Comum para Formação de Professores da Educação Básica (BNC-Formação e (BNC-Formação Continuada), problematizando as noções relacionadas aos direitos de aprendizagem, espectro de justiça e a responsabilização docente, em detrimento dos sentidos mais amplos do Direito à Educação. Do ponto de vista teóricometodológico, a nossa proposta se pauta numa leitura pós-estrutural das políticas de currículo para formação de professores homologadas pelo Conselho Nacional de Educação em 2019 e 2020, em diálogo com Bhabha (1998), Macedo (2006), Derrida (2010), com vistas a desconfiar dos sentidos em que se veiculam as ideias de direito nas políticas instituídas no governo atual.

No deslocamento do que se define por Direito à Educação ao que vem sendo nomeado nos documentos como "direitos" de aprendizagens, mas que na nossa percepção pode também ser considerado "deveres" da ação docente, ingressam no jogo de significações diferentes questões que hora convergem (aparentemente) para o mesmo ponto, hora divergem, intensificando as questões que merecem aprofundamento e que são pensadas aqui, não como questões dicotômicas, mas como constitutivas entre si inerentes aos aspectos performáticos das políticas. "Retomando os quase-conceitos derridianos, a performance seria esse ato potente de deslocar a lógica estabelecida como hegemônica e não permitir-se capturar por ela: sendo khôra, rastro e deslocamentos." (Saraiva, 2014, p. 03)

De acordo com Derrida (2010) consideramos que não há direito sem força uma vez que "o direito é sempre uma força autorizada, uma força que se justifica ou que tem aplicação justificada, mesmo que essa justificação possa ser julgada, por outro lado, justa ou injusta.” (Derrida, 2010, p. 7-8). Direito e justiça, nesse entendimento, tem uma relação estranha, que não são sinônimas, nem natural, mas se constituem no território das significações que colocam em jogo vários sentidos, disputas de diferentes projetos sociais e interesses. Optamos por desenvolver o artigo em dois momentos, a saber: primeiro discutiremos as concepções de direito à educação e o espectro de justiça que envolvem a política de formação docente no Brasil. E na segunda parte, desenvolveremos uma análise pontual da política governamental da Base Nacional Comum para Formação de Professores da Educação Básica (BNC-Formação e BNC-Formação Continuada).

\section{Em foco o direito à educação e o espectro de justiça como jogo político}

O cenário educacional brasileiro tem sido tema de diversas discussões que, geralmente, fazem alusão às dificuldades do sistema educacional nacional. Não obstante, são remetidos aos índices dos resultados das avaliações internacionais difundidos pela mídia, que listam o Brasil em situação crítica em relação ao mundo, no que diz respeito ao seu desenvolvimento educacional. A "qualidade" e a "igualdade" são pontuadas pela Organização das Nações 
Unidas para Educação, a Ciência e a Cultura - UNESCO como desafios cruciais que precisam ser enfrentados pelo Brasil e pelo mundo, considerados essenciais para o atendimento das necessidades e para a construção da "nova linguagem da aprendizagem" (Biesta, 2017). Aponta-se inclusive que "pesquisas mostram que grande parcela dos alunos de diferentes níveis educacionais apresenta deficiências de aprendizagem em disciplinas críticas. A baixa absorção de conceitos científicos prejudica a inclusão desses indivíduos na sociedade moderna" (Unesco, s/d) ${ }^{1}$.

Compartilhamos da ideia de que "a defesa de uma base nacional comum para o currículo tem funcionado como uma das muitas promessas de dar qualidade à educação para diferentes grupos da sociedade" (Macedo, 2014, p. 1537). Em um campo de disputas de significação deste currículo, as lutas por significação dos sentidos, assumem nesse fluxo, discursos que tendem a produzir força nessa produção. Direito de aprendizagem acaba por ser significante de fácil adesão, uma vez que não se nega a necessidades de direito a uma escola de qualidade em que os estudantes aprendam o que lhes é ensinado.

$\mathrm{O}$ vínculo entre aprendizado com o enfoque no compromisso com as transformações sociais é percebido nas políticas de formação docente, indicando a necessidade de mudanças no contexto educacional global. Segundo consta no site da UNESCO, será pela mobilização dos atores sociais que poder-se-á contribuir para a promoção da cidadania, consolidação da democracia, promoção da igualdade, acesso amplo à justiça e garantia da segurança, aspectos fundamentais para consolidar uma cultura de direitos humanos e cultura de paz.

$\mathrm{O}$ direito à educação nesse sentido vincula-se não somente a dimensão individual das pessoas, mas pela relação que agrega o acesso à educação como promessa de desenvolvimento social. Essa é uma dimensão do direito que vincula o que é singular ao que é coletivo, na perspectiva do direito público subjetivo ${ }^{2}$. O termo "direito" como perspectiva de um bem a ser garantido, desperta o interesse a respeito das nuances do seu uso nos diferentes contextos. Educação como direito de todos é abordada como uma possibilidade de engendrar nesses sentidos.

Em relação ao direito no contexto educacional, ressalta-se o cuidado às diferentes abordagens, concepções e multiplicidade de entendimentos que não encerram a discussão, ao contrário, mostra-nos da necessidade de aprofundarmos e da responsabilidade na proposição de investigações que contribuam no debate político. Neste contexto, ao tomar o direito como categoria analítica das políticas educacionais nas questões tratadas nessa pesquisa, consideramos que precisamos romper com a ideia de direito como manejo normativo de técnicas jurídicas, ao mesmo tempo que não deixamos de considerar tais normas em sua dimensão cultural.

Temos clareza que as leis não são criadas a partir do nada, são produzidas considerando as situações impostas pelas relações sociais, a partir das quais criam-se normas, parâmetros e regulamentos na tentativa de organização da vida em sociedade, essa produção, contudo, não se dá a partir de elementos neutros, desconectados de interesses e de relações de poder. Ao indagar as normas instituídas, questionar os conceitos com os quais são registradas, problematizar algumas interpretações dos fundamentos que as sustentam e os sentidos de sua aplicação e intencionalidades, a intenção é operar com resquícios desse desmonte, com vistas 
a incluir na pauta, de discussões sobre a temática, questões que por vezes são silenciadas ou excluídas.

Bobbio (2004, p. 31) explica que "é com o nascimento do Estado de direito que ocorre a passagem final do ponto de vista do príncipe para o ponto de vista dos cidadãos". Comenta que quando os indivíduos só têm deveres e não tem direitos, é o Estado despótico. "No Estado de direito, o indivíduo tem, em face do Estado, não só direitos privados, mas direitos públicos". E completa dizendo que, "o Estado de direito é o Estado dos cidadãos" Frente a isso, nasce a necessidade de nova especificação sobre sujeito? Para Bobbio, o retorno à história é uma estratégia de possibilidades de releituras, considerando que também a história não é uma só. Compreendemos, contudo, que discursividade se constitui também enquanto rastro de uma temporalidade não linear, o que nos permite, nesse entendimento, problematizar tanto a noção de sujeito, quanto da historicidade do direito. No que tange essa pesquisa, que professor atende as necessidades do Estado para garantir o direito à aprendizagem?

Diante das necessidades impostas de se pensar um perfil docente, compreendemos que a uma política de formação de professores reflete uma prática de negociação, que envolve a "habilidade de articular diferenças no espaço e tempo, de ligar palavras e imagens em novas ordens simbólicas, de intervir na floresta de sinais e de mediar o que parecem ser valores incomensuráveis ou realidades contraditórias." (Bhabha, 2011, p.97)

No momento em que o preceito tenta se objetivar como um conhecimento generalizado ou uma prática normalizante e hegemônica, a estratégia ou o discurso híbrido inaugura um espaço de negociação, onde o poder é desigual, mas a sua articulação pode ser questionável. Tal negociação não é nem assimilação, nem colaboração. Ela possibilita o surgimento de um agenciamento "intersticial", que recusa a representação binária do antagonismo social. (Bhabha, 1998, p.91)

Assim, produz-se o jogo político, que não significa pensar a negociação a partir de uma ideia de barganha, mas como articulação. Sob o enfoque da noção de discurso, não se pode considerar identidades e movimentos discursivos como elementos fechados e determinados, mas sim como campos de significação, que são considerados por Laclau e Mouffe (2015) a partir de três noções fundamentais: a de elemento, a de momento e a de prática articulatória.

[...] chamaremos de articulação qualquer prática que estabeleça a relação entre elementos tal que suas identidades sejam modificadas como um resultado da prática articulatória. A totalidade estruturada resultante da prática articulatória nós chamaremos de discurso. As posições diferenciais na medida em que elas aparecem articuladas dentro do discurso, nós chamaremos de momentos. Por contraste, nós chamaremos elementos qualquer diferença que não seja discursivamente articulada. (LACLAU e MOUFFE, 2015, p. 178)

A prática articulatória define-se pela articulação de elementos que estão submersos numa lógica complexa (lógica da diferença) e que se encontram separados em relação aos demais pelo campo da discursividade; ao agregar os elementos, a prática articulatória os transforma 
em momentos (elementos equivalentes), que ao assumirem tal condição tornam-se um momento diferencial, deixando então o seu status de elemento; é na articulação dos momentos diferenciais (pontos nodais) que ocorrem as modificações das identidades dos sujeitos, que passam por uma alteração das condições particulares anteriores (Mendonça, 2003).

Ao discutir os conceitos de direito e justiça, Derrida comenta que "não se pode falar diretamente da justiça, tematizar ou objetivar a justiça, dizer "isso é justo" e, ainda menos, "eu sou justo", sem trair imediatamente a justiça, senão o direito" (Derrida, 2010, p 17). Tratar aqui de justiça então, é considerar sua condição espectral, uma vez que o direito, é a instituição de regra em que a justiça cobra respostas. E, como fantasma, assombra critérios de vida e morte, de presença e ausência, colocando em xeque critérios de verdade, certezas que o direito tenta impetrar, ameaçando uma certa objetividade necessária ao direito, mantendo abertas a experiencia da aporia. "Justiça seria, desse ponto de vista, a experiência daquilo que não podemos experimentar [...] ao mesmo tempo em que "a justiça é a experiência do impossível" (Derrida, 2010, p. 30). Sendo apenas apelo, clamor, sem nunca chegar a ser.

A opção por estudar a Base Nacional Comum para Formação de Professores da Educação Básica (BNC-Formação e BNC-Formação Continuada) parte do entendimento que as propostas se constituem como políticas curriculares centralizadoras que se adensam na contemporaneamente a partir do seu apelo à justiça. Tais políticas são intituladas como instrumentos para promoção da equidade através da definição de aprendizagens essenciais, cujo objetivo é balizar as demais políticas educacionais de todo o país, sob a pretensa promessa de papel decisivo na formação integral dos sujeitos e na construção de uma sociedade justa, democrática e inclusiva. Essa condição que nos faz questionar os modos como os argumentos da garantia de acesso aos direitos de aprendizagem, foram definidos como arranjo que justificou a criação do que foi nomeado por conjunto de aprendizagens a que todos os alunos têm por direito de "aprender" e que todos os professores precisam "ensinar".

A ideia da educação como direito de todos produz, em certa medida, a crença da necessidade de educar nossa humanidade, seja ela marcada por concepções de inserção e adaptação humana ou por perspectivas que estão focadas no cultivo da pessoa humana (individual). Contudo, entre o que se entende por educação e ação docente produzem-se sentidos e configuram modos no jogo político, que por sua vez, vão produzindo sentidos de direito educacional.

Não se trata de responder a questão encontrando na política instituída um "conspirador" que deseja subjugar os oprimidos ou do investimento na emancipação dos sujeitos, mas compreender como discursos têm sido construídos marcando e sendo marcados pelas diferentes formas de leitura do contexto político, procurando compreender ainda, através das impressões das leituras dos autores com os quais dialogamos, o processo de inclusão e exclusão de interesses, valores e concepções. Por isso, mais que entender a história como resposta, procuramos considerar uma perspectiva contingencial, em que diferentes discursos são produzidos ao mesmo tempo que produzem diferentes sentidos. 
A partir dos estudos de Derrida (2010) e Laclau (2011), consideremos que os autores encontram em "Espectros de Marx" possibilidades de pensar alguns aspectos da pesquisa que por vezes nos colocam em conflito, tendo em vista o momento político atual, caracterizado pelas aparentes "perdas de conquistas" políticas, principalmente nos contextos educacional e trabalhista - uma vez que "O abismo entre lei e justiça é algo que não pode ser fechado", torna as reinvindicações por justiça, multifacetados e complexos. (Laclau, 2011, p. 118)

Nesse sentido, como tratar de questões que dizem respeito ao direito, na proposta de colocá-los sob suspeita, em tempos em que temos perdido tantos direitos? Haverá lugar para questionar os direitos à educação? Qual a intenção nesse intento, considerando a perda da autonomia e a responsabilização docente?

No que tange ao sentido espectral da justiça, emancipação e democracia, França (2013) a partir dos estudos de Derrida são compreendidos como promessa:

Para além mesmo dessa ideia reguladora em sua forma clássica, a ideia, caso ainda seja uma ideia, da democracia por vir, sua ideia como acontecimento de uma injunção penhorada que prescreve fazer vir isto mesmo que não se apresentará nunca na forma da presença plena, é a abertura deste desvio entre uma promessa infinita (sempre insustentável, quando menos, porque exige o respeito infinito pela singularidade e a alteridade infinita do outro assim como pela igualdade contável, calculável e subjectal entre as singularidades anônimas) e as formas determinadas, necessárias, mas necessariamente inadequadas, do que se deve medir com essa promessa. (Derrida, 1994, p.92-93, apud França, 2013, p. 209210)

Os perigos desta postura, pontuados por Laclau, não excluem a consideração às provocações de Derrida, esclarecendo que, o que ele quer dizer é que demandas isoladas, injustiças, queixas etc, são sintomas de um impasse das sociedades contemporâneas, deslocando essas demandas isoladas para "algum tipo de articulação fantasmática, de que resultarão novas formas de reagregação política.” (Laclau, 2011, p. 121)

Os termos utilizados por Derrida, como justiça, democracia, espectro, acontecimento, caracterizam uma certa inadequação, em que o lugar vazio e a estrutura de espectralidade abrem campo de (im)possibilidades. "É a manutenção dessa abertura que pode talvez transformar a vida política na direção de um ideal renovado e mais elevado de emancipação." (França, 2013, p. 212)

No processo de construção de políticas públicas que trazem em seu discurso a necessidade da construção de uma sociedade justa, democrática e inclusiva, aproveita-se das aberturas do jogo político, criando reinvindicações, que articulam nesse processo os vínculos postulados na ideia de que é preciso instituir "direitos de aprendizagem" atrelados à lógica de uma unidade (nacional) comum a todos os brasileiros. Essa lógica vem revestida de fins democráticos e do pensamento de uma possível garantia de justiça social, entendendo justiça como igualdade. Nesse sentido, carrega a ideia de justiça social como algo homogêneo, tornar algo "comum" não necessariamente estabelece a democracia. 
Para Derrida (2010) atender um direito não é, necessariamente, garantir "justiça". A democracia não poderia, dessa forma, ser compreendida como decorrência "natural" do acesso ao direito. Para ele, o direito se relaciona com a justiça de modo aporético, por pertencer à ordem do cálculo, enquanto a justiça é incalculável porque se refere à singularidade do absolutamente outro. A garantia de um direito não necessariamente o é de justiça, pois justiça requer singularidade. Segundo ele, "É preciso também saber que essa justiça se endereça sempre a singularidades, à singularidade do outro, apesar ou mesmo em razão de sua pretensão à universalidade." (Derrida, 2010, p.37)

\section{Em foco as políticas de formação docente...}

Ao trabalharmos nessa leitura das políticas de formação de professores, engendramos no entendimento de que tais políticas incidem sentidos na produção curricular dos diferentes contextos educacionais, o que difere do entendimento que reduz o currículo às prescrições. Nesse sentido, concordamos com Macedo (2006) que "parte de nossa agenda política, como pesquisadores do campo, a necessidade de pensarmos um conceito de currículo que o conceba como espaço de produção cultural para além dessas dicotomias" (p. 99-100). Desta forma, buscamos compreender o currículo como um híbrido, no qual "as culturas negociam com-a-diferença." (Macedo, 2006, p. 105), por considerarmos que ao atrelar currículo e formação de professores estabelece conflitos e negociações, principalmente quando o Ministério da Educação argumenta que a: "[...] BNC-Formação é baseada em três eixos que vão nortear a formação inicial e continuada dos docentes de todo o país: conhecimento, prática e engajamento" (Brasil, 2018a, n.p. grifos nossos)[1].

No que tange ao direto à educação e ao espectro da justiça, a Resolução $\mathrm{CNE} / \mathrm{CP} \mathrm{n}^{\circ} 1$, de 27 de outubro de 2020, que institui que dispõe sobre as Diretrizes Curriculares Nacionais para a Formação Continuada de Professores da Educação Básica e institui a Base Nacional Comum para a Formação Continuada de Professores da Educação Básica (BNC-Formação Continuada, ressalta todo o processo de responsabilização docente e institucional que por meio da justiça busca instituir regras, assim como cobrar respostas. Como destacamos a seguir:

V - Reconhecimento e valorização da materialização objetiva do direito à educação dos alunos como principal função social da instituição escolar, da atuação profissional e da responsabilidade moral dos docentes, gestores e demais funcionários, de acordo com:

a) o artigo 26 da Declaração Universal dos Direitos Humanos, visando à plena expansão da personalidade humana, o reforço dos direitos do Homem e das liberdades fundamentais, favorecendo a compreensão, a tolerância e a amizade entre todas as nações e todos os grupos raciais ou religiosos e uma cultura de paz; e

b) o Estatuto da Criança e do Adolescente, em particular os artigos $5^{\circ}, 6^{\circ}, 15,16$, 17, 18 e 18-A, respeitando explicitamente quanto ao acolhimento, atenção, 
responsabilidade na valorização da dignidade individual e coletiva dos alunos, respeito às limitações, peculiaridades e diferenças, além das formas adequadas de relacionamento, estímulo ao desenvolvimento integral dos alunos com atenção para seus direitos, deveres e formação ética;

c) as diretrizes do Plano Nacional de Educação; e

d) a Base Nacional Comum Curricular em vigência. (BRASIL, 2020)

A aplicabilidade da lei é por si, força que, segundo Derrida (2010), está essencialmente implicada no conceito de justiça enquanto direito. "Da justiça na medida em que se torna lei, da lei enquanto direito". Em outras palavras, "por aplicar" a lei perde-se aquela alusão direta, literal, à força que vem do interior, lembrando-nos que o direito é sempre uma força autorizada, uma força que se justifica ou se tem aplicação justificada, mesmo que essa justificação possa ser julgada, por outro lado, injusta ou injustificável. (Derrida, 2010, p. 08)

Ao destacar os eixos norteadores da BNC-Formação, considera-se aspectos que reforçam a desvalorização e responsabilização docente, tanto dos professores responsáveis pela formação inicial, quanto dos que já estão atuando na educação básica. Na nossa acepção, a proposta redimensiona a formação de professores a perspectiva da falta, diante de uma noção de política que se alinha ao viés da reparação, que carregam sentidos da falta de formação adequada e do não saber docente. A leitura possível é que o "fracasso" educacional brasileiro, tem endereço certo, atrela-se a isso, a responsabilização docente que imputa aos professores, a 'responsabilidade do fracasso educacional brasileiro' dada a formação inadequada. Como o MEC argumenta como premissa para a implantação da BNC-Formação:

A premissa da proposta da BNC-Professores são os recorrentes resultados insuficientes de aprendizagem dos estudantes e da baixa qualidade da formação dos docentes. Em geral, os cursos contam com muita teoria e pouca prática, falta aprofundamento na formação inicial para a educação infantil, alfabetização e anos iniciais, além de estágios curriculares sem planejamento e sem vinculação com as escolas (Brasil, 2018, n.p[2]).

A proposta da Base Nacional Comum (BNC-Formação e BNC-Formação Continuada) além de buscar via direito à aprendizagem, traz em seu jogo político todo um discurso desqualificador da formação dos professores, tanto do ponto de vista inicial quanto continuada, por isso tem por premissa o trabalho por competências e habilidades na Base Nacional Comum Curricular para os alunos em consonância com uma perspectiva formativa da ação docente. $\mathrm{O}$ alinhamento já era previsto no $\operatorname{artigo}{ }^{\circ}, \S 1^{\circ}$, e no $17^{\circ}$ artigo da Resolução do $\mathrm{CNE} / \mathrm{CP}^{\circ}{ }^{\circ}$ 2, de 22 de dezembro de 2017, que instituiu a BNCC. A saber:

Art. $5 \S^{\circ}$ A BNCC deve fundamentar a concepção, formulação, implementação, avaliação e revisão dos currículos, e consequentemente das propostas pedagógicas das instituições escolares, contribuindo, desse modo, para a articulação e coordenação de políticas e ações educacionais desenvolvidas em âmbito federal, estadual, distrital e municipal, especialmente em relação à formação de 
professores, à avaliação da aprendizagem, à definição de recursos didáticos e aos critérios definidores de infraestrutura adequada para o pleno desenvolvimento da oferta de educação de qualidade.

Art. 17. Na perspectiva de valorização do professor e da sua formação inicial e continuada, as normas, os currículos dos cursos e programas a eles destinados devem adequar-se à BNCC, nos termos do $\$ 8^{\circ}$ do Art. 61 da LDB, devendo ser implementados no prazo de dois anos, contados da publicação da BNCC, de acordo com Art. 11 da Lei no 13.415/2017.

De acordo com o documento "[...] a BNCC deverá ser, daqui em diante, uma referência para a formação inicial e continuada dos professores. Abre-se assim uma janela de oportunidade para debater alguns dos entraves e dar qualidade à formação do professor brasileiro" (Brasil, 2018b, p.7). Cabe destacar que "dar qualidade" trata-se de um discurso

Considerando o exposto, as premissas da BNC-Formação reforçam a importância de trabalhar o eixo do conhecimento, tendo o docente que "[...] dominar os conteúdos e saber como ensiná-los, demonstrar conhecimento sobre os alunos e seus processos de aprendizagem, reconhecer os diferentes contextos e conhecer a governança e a estrutura dos sistemas educacionais". No que tange à prática, o documento ressalta a importância do planejamento e das práticas pedagógicas, relacionando o "[...] criar e gerir ambientes de aprendizagem e ter plenas condições de avaliar a aprendizagem e o ensino", de modo a orientar o trabalho docente para os objetos do conhecimento, competências e habilidades presentes na Base Nacional Comum Curricular, que é o norte do trabalho das escolas (Brasil, 2018a, n.p).

Ao abordar o eixo do engajamento, a proposta almeja que "[...] professor se comprometa com seu próprio desenvolvimento profissional, com a aprendizagem dos estudantes", assim como precisa ser engajado com a comunidade escolar" (Brasil, 2018a, n.p). Em síntese, são atribuídas ações diretivas ao saber-prática pedagógico e que responsabilizam os professores pela qualidade do ensino no país.

Não diferente do que a BNC-Formação, a Base Nacional Comum para a Formação Continuada de Professores da Educação Básica (BNC-Formação Continuada), em seu artigo 50, IV destaca: "reconhecimento e valorização dos docentes como os responsáveis prioritários pelo desenvolvimento cognitivo, acadêmico e social dos alunos, a partir de uma formação sólida que leve em conta o conhecimento profissional; a prática profissional; e o engajamento profissional" (Brasil, 2020, p. 2. grifos nossos). Ao trabalhar as dimensões para a formação continuada, o documento destaca também a "responsabilidade moral dos docentes, gestores e demais funcionários: conhecimento profissional" (ibidem, p.2. grifos nossos), que reflete a necessidade da "[...] aquisição de conhecimentos específicos de sua área, do ambiente institucional e sociocultural e de autoconhecimento"; prática profissional, sendo essa subdivida em: pedagógica, que requer o desenvolvimento de competências relativas "aos aspectos didáticos e pedagógicos" e institucional, que atrela a perspectiva formativa à "cultura organizacional das instituições de ensino e do contexto sociocultural em que está inserido" e; engajamento profissional, que reforça a necessidade do 
"comprometimento com a profissão docente assumindo o pleno exercício de suas atribuições e responsabilidades" (Brasil, 2020, p. 8-9).

A partir da análise é notório toda uma ação política voltada à formação de professores e currículo, pautada na autorregulação e performance, a saber:

$\mathrm{O}$ que se pretende controlar com a finalidade de padronizar currículos acaba também por projetar modos de ser professor a partir de uma ideia-base sobre a educação. Objetivos de controle que se enunciam nos textos das políticas curriculares para a formação docente buscam a autorregulação desses profissionais no cumprimento de metas de resultados em relação ao desempenho dos estudantes, da escola e dos professores, e acabam influenciando o conteúdo de sua formação, inicial ou continuada. Processos de performatividade reduzem o trabalho dos professores ao que eles podem produzir apenas no contexto da eficiência e da eficácia do ensino. (Dias; Ponce, 2015, p. 612)

A perspectiva de pensar o currículo como espaço de produção cultural, em diálogo com Macedo (2006) e Bhabha (1998), nos permite argumentar que a BNC-Formação e BNCFormação Continuada recorrem à prática curricular, que não só define o que ensinar, mas como ensinar. Numa perspectiva pós-colonial, consideramos que as premissas que envolvem as políticas de currículo para formação de professores trata-se de uma produção de sentidos e significados, que trazem junto bandeiras como justiça social, luta pela igualdade, foco no político e desenvolvimento de uma agenda de transformação social em direção a relações de poder menos excludentes do ponto de vista econômico.

Ao optarmos por trabalhar dentro da teorização pós-colonial, o lócus de análise passa ser o da enunciação - ser de, vir de e estar em -, o que possibilita pensar a questão da BNC como entrelugar de vozes silenciadas, discriminadas e estereotipadas em diálogo com os demais sujeitos presentes nos espaços de poder; mas um poder que não é mais definido como única via de força e sim como lugar de negociação e de ambivalência das diferentes formas que nós criamos para aprender a lidar com ele (Bhabha, 1998).

O currículo, numa visão pós-colonial, não pode ser pensado apenas "como objeto de contemplação epistemológica ou moral: as diferenças culturais não estão simplesmente lá para serem vistas ou apropriadas" (BHABHA, 1998, p. 165-166). Diante disso, concordamos com Macedo (2006) que é

[...] possível tratar os currículos numa perspectiva pós-colonial, na medida em que não entendo o colonialismo como uma dominação política e econômica, mas fundamentalmente como um processo cultural, como uma tentativa de espraiar pelo mundo uma única forma legítima de criação de significados. Nesse sentido, nossos currículos são também um lugar-tempo em que essa forma é vivida, assim como o são artefatos culturais como livros, filmes, obras de arte. (p. 104)

Os eixos que orientam o argumento dos documentos analisados, articulam entre si, a dimensão do conhecimento significado pela técnica que alia modo de ensinar e o que ensinar, 
para que se garanta na prática a "aprendizagem efetiva", resultado, por sua vez, do "engajamento" docente. Abordar então a relação ao que é significado por conhecimento esperado dos processos de formação inicial e continuada, é necessário considerar alguns aspectos pelos quais Biesta (2017) chama atenção em relação ao crescimento do conceito de aprendizagem em detrimento ao conceito de educação. Segundo ele, "[...] a linguagem da educação tem sido em grande parte substituída por uma linguagem da aprendizagem." (p.30), e explica que algo se perdeu nessa mudança.

Para Biesta (2017), um dos modos de perceber o surgimento das novas aprendizagens pode estar relacionado com o desenvolvimento socioeconômico e político dos últimos tempos. As ideias do autor reforçam uma "[...] lógica que focaliza quase exclusivamente o usuário ou consumidor do serviço educacional. Que nome poderia ser mais adequado para esse consumidor do que “o aprendente"?” (p. 37).

O principal problema com a nova linguagem da aprendizagem é que ela tem facilitado uma nova descrição do processo da educação em termos de uma transação econômica, isto é, uma transação em que (1) o aprendente é o (potencial) consumidor, aquele que tem certas "necessidades", em que (2) o professor, o educador ou a instituição educacional são vistos como provedor, isto é, aquele que existe para satisfazer as necessidades do aprendente, e que (3) a própria educação se torna mercadoria - uma "coisa" - a ser fornecida ou entregue pelo professor ou pela instituição educacional, e a ser consumida pelo aprendente. (Biesta, 2017, p. 38)

Assim, cabe ao professor portar-se como fiel ao público consumidor das aprendizagens, cumprir os modelos educacionais oferecendo a estes o que subjaz às suas necessidades. Tais necessidades são previamente definidas, a partir de uma estrutura única, significada pela eficiência e eficácia no processo, priorizando as questões técnicas. O discurso difundido nas políticas, forjam-se, cada vez mais, nessa ideia de aprendizagem como nova linguagem da educação. Nesse sentido, argumentamos que esta reflexão passa pela problematização dos sentidos do que venha ser direito fundamental, restringe-se ao "aprender" e aprender um conjunto de conhecimentos construídos e definidos como patrimônio universal. É possível considerar os sentidos de direitos de aprendizagem constituem modos simplificados que reduzem as possibilidades de direito à educação.

\section{Considerações finais}

A articulação do discurso da aprendizagem, engajamento docente e os direitos de aprendizagem, marcam um viés que inferem à docência a responsabilidade nos resultados dos investimentos das políticas educacionais, que se constituem, nesse entender, suficientes para o enfrentamento dos problemas educacionais brasileiros. À formação - inicial ou continuada - dos professores caberá a mera preparação para execução da BNCC, assim como a responsabilização sobre os resultados da política. 
Encontramos nas abordagens discursivas, possibilidades de um engajamento outro, que se postula em uma luta por significação, em que ao mesmo tempo os acontecimentos "tem de ser lidos de outro modo, transformados nos atos de governos e no discurso da autoridade em outro lugar, em outro tempo.” (Bhabha, 1998, p. 141). Consideramos que as políticas curriculares voltadas para a formação de professores reforçam o poder regulatório e normativo do governo, assim como propõem um projeto pautado no desempenho, na excelência e na eficiência da prática dos professores a partir de mecanismos de avaliação interna e externa. Ao mesmo tempo, transferir responsabilidade pela aprendizagem para os professores e instituições, resulta num movimento de perda de autonomia docente e de identidade profissional.

A nosso ver, quando as ações pedagógicas e o "sucesso" pela aprendizagem passam a ser responsabilidade do professor, está se assumindo o discurso do "engajamento" docente presentes nos documentos analisados, que articulam ao mesmo tempo os conceitos de liberdade, responsabilidade e autonomia, por meio de aplicação de estratégias didáticas postuladas pelo conhecimento, prática e engajamento do professor.

Ao atravessar a questão da autonomia docente, a proposta da Base Nacional Comum para Formação de Professores da Educação Básica - que requer o exercício de suas atribuições e responsabilidades para garantir a justiça social via educação - também afeta a identidade profissional. Em outras palavras, o professor no exercício profissional tem sua identidade ressignificada a partir de um conjunto de competências e habilidades a serem ensinadas de modo a garantir a qualidade requerida nas políticas de avaliações em larga escala.

Concluímos destacando que a justiça é requerida em situações de exaustão dos padrões sociais aceitáveis, mas consideramos que a pura aplicação da lei não define a justiça. Por justiça, inclui-se pensar nas singularidades excluídas na produção das normas. Aplicar a regra não se articula em tomada de decisão, mas em seguir uma lei, desse modo, não se pode dizer que foi justo ou injusto, simplesmente, porque para exercer a justiça ou violá-la, devo ser livre e responsável por minha ação. (Derrida, 2010)

A noção de justiça então, tem caráter diferente, dependendo dos conceitos que a fundamentam. Seja pela teoria de justiça distributiva ou corretiva, uma que considera todos iguais ou dada medida ao que cada um merece, seja pela igualdade absoluta ou proporcional, instala-se sempre em um tênue limite de assombração do indecidível. Nosso questionamento sobre as dimensões nas quais o direito e a justiça são significados nas políticas, não se pauta no aniquilamento dos direitos conquistados ou da busca por justiça, ao contrário, é também postura política, compreendemos que tal exercício constitui-se um caminho que possamos ampliar as possibilidades de pensarmos a justiça como mera aplicabilidade da lei para construção de outras formas de inscrição. 
Notas:

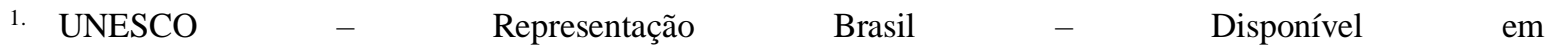
http://www.unesco.org/new/pt/brasilia/education/educational-quality/ Acesso em 11/5/2017.

2. "O Jurista alemão Georg Jellinek, cuja obra, publicada em 1892, é um marco para a temática, definiu esta figura jurídica como sendo "o poder da vontade humana que, protegido e reconhecido pelo ordenamento jurídico, tem por objeto um bem ou interesse" (Jellinek, 1990, p.10) Trata-se de uma capacidade reconhecida ao indivíduo em decorrência de sua posição especial como membro da comunidade, que se materializa no poder de colocar em movimento normas jurídicas no interesse individual. Em outras palavras, o direito público subjetivo confere ao indivíduo possibilidade de transformar a norma geral e abstrata contida em determinado ordenamento jurídico em algo que possua como próprio" (DUARTE, 2004, p.113).

\section{Referências}

BRASIL. Proposta de novas normas para a formação do professor avança. Ministério de Educação. Assessoria de Comunicação Social, 2018a. Disponível em: http://portal.mec.gov.br/component/tags/tag/bnc-professor. Acesso em 10/06/2021.

BRASIL. Proposta para Base Nacional Comum da Formação de Professores da Educação Básica, 2018 b. Disponível em: http://portal.mec.gov.br/index.php?option=com_docman\&view=download\&alias=105091-bnc-formacaodeprofessores-v0\&category_slug=dezembro-2018-pdf\&Itemid=30192. Acesso em 15/08/2019.

BRASIL. RESOLUÇÃO CNE/CP $\mathbf{N}^{\circ}$ 2, DE 20 DE DEZEMBRO DE 2019. Ministério Da Educação/Conselho Nacional de Educação, 2019. Disponível em: http://portal.mec.gov.br/docman/dezembro-2019-pdf/135951-rcp002-19/file. Acesso em 10/08/2020.

BRASIL. RESOLUÇÃO CNE/CP No 1, DE 27 DE OUTUBRO DE 2020. Ministério Da Educação/Conselho

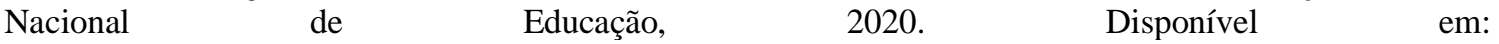
http://portal.mec.gov.br/index.php?option=com_docman\&view=download\&alias=164841-rcp00120\&category_slug=outubro-2020-pdf\&Itemid=30192. Acesso em 10/02/2021.

BHABHA, Homi K. O local da cultura. Belo Horizonte: Ed. UFMG, 1998.

. O bazar global e o clube dos cavalheiros ingleses: textos seletos de Homi Bhabha. Organização de Eduardo F. Coutinho. Rio de Janeiro, Rocco, 2011.

BIESTA, Gert. Para Além da Aprendizagem: Educação Democrática para o futuro humano. Belo Horizonte: Autêntica Editora, 2017.

BOBBIO, Norberto. A Era dos Direitos. Tradução Carlos Nelson Coutinho. Rio de Janeiro, Elsevier, 2004. $7^{\text {a }}$ reimpressão.

DERRIDA, Jacques. Força de Lei: o fundamento místico da autoridade. São Paulo: Editora WMF Martins Fontes, 2010. $2^{\mathrm{a}}$ Edição.

DIAS, Rosanne Evangelista; PONCE, Branca Jurema. Formação docente frente às políticas no cenário de centralização curricular. Revista e-Curriculum, São Paulo, v.13, n.04, p. 612 - 615 out./dez.2015. Disponível em http://revistas.pucsp.br/index.php/curriculum. Acesso em 21 jun. 2021.

DUARTE, Clarice Seixas. Direito Público Subjetivo e Políticas Educacionais. São Paulo em Perspectiva, 18(2): 113-118, 2004.

FRANÇA, Thiago. Justiça como espectro e democracia por vir: as consequências políticas da desconstrução. Sapere Aude - Belo Horizonte, v.4 - n.7, $1^{\circ}$ sem. 2013. p.198-212. 
LACLAU, Ernesto; MOUFFE, Chantal. Hegemonia e estratégia socialista: por uma política democrática radical. São Paulo: Intermeios; Brasília: CNPq, 2015.

LACLAU, Ernesto. Emancipação e diferença. Rio de Janeiro: EdUERJ, 2011.

MACEDO, E. Currículo como Espaço-Tempo de Fronteira Cultural. Revista Brasileira de Educação, v.11, n.32, maio/ago., 2006. p. 285-296.

"Base Nacional Curricular Comum: novas formas de sociabilidade produzindo sentidos para educação. Revista e-curriculum 12.3 (2014), p. 1530-1555.

MENDONÇA, Daniel. A noção de antagonismo da ciência política contemporânea: uma análise a partir da perspectiva da teoria do discurso. Revista de Sociologia e Política, Curitiba, $n^{\circ}$ 20, jun. 2003. p. 135-145.

SARAIVA, Letícia Cristina. Estética latina: a arte faz-se popular - o não-lugar e a desconstrução feminina. $\mathbf{2 3}^{\mathbf{o}}$ Encontro da ANPAP. Belo Horizonte/MG, 2014. Disponível em: http://anpap.org.br/anais/2014/simposios/simp\%C3\%B3sio06/Let\%C3\%ADcia\%20Cristina\%20Saraiva.p df. Acesso em 21 jun. 2021.

\section{Correspondência}

Débora Barreiros: Graduada em Pedagogia pela Universidade Federal do Rio de Janeiro (1996-1999), com Mestrado em Educação pela Universidade do Estado do Rio de Janeiro (2001-2003), Doutorado em Educação (2006-2009) e Pós-Doutorado em Educação (2009-2012) na mesma instituição. Professora adjunta da Universidade do Estado do Rio de Janeiro. Pesquisadora integrante dos GrPESq/CNPq Currículo, Formação e Educação em Direitos Humanos. Coordenadora do Curso de Pedagogia e do Curso de Pós-Graduação em Psicopedagogia Clínica e Institucional da Universidade Estácio de Sá Campus Madureira. Pesquisadora do Grupo de Pesquisa Currículo, Formação e Educação em Direitos Humanos. Membro da Associação Brasileira de Currículo (ABdC) e da Associação Nacional de Pósgraduação e Pesquisa em Educação (ANPEd). Tem experiência na área de Educação, com ênfase em teoria curricular, atuando principalmente nos seguintes temas: currículo, didática, avaliação, cultura, identidade e diferença.

E-mail: dbarreiros@gmail.com

Rosalva de Cássia Rita Drummond: Doutora em Educação pelo Programa de Pós-Graduação em Educação, Universidade do Estado do Rio de Janeiro. Professora no Curso de Pedagogia no Instituto Superior de Educação do Rio de Janeiro e da Universidade Estácio de Sá. Pesquisadora do Grupo de Pesquisa Currículo, Formação e Educação em Direitos Humanos. Membro da Associação Brasileira de Currículo $(\mathrm{ABdC})$; Associação Brasileira de Alfabetização (ABAlf) e da Associação Nacional de Pós-graduação e Pesquisa em Educação (ANPEd). Tem se dedicado ao estudo na área de Educação, com ênfase em Políticas Curriculares, Currículo, Formação de Professores, Educação Infantil, Anos Iniciais, Alfabetização.

E-mail: rosalvadrummond@gmail.com

Texto publicado em Currículo sem Fronteiras com autorização dos autores. 